\title{
Comparison of Cross-Laminated Timber and Reinforced Concrete Floors with Regard to Load-Bearing Properties
}

\author{
Alireza Bahrami*, Andreas Vall, Asaad Khalaf \\ Department of Building Engineering, Energy Systems and Sustainability Science, Faculty of Engineering and Sustainable \\ Development, University of Gävle, 80176 Gävle, Sweden
}

Received May 7, 2021; Revised June 4, 2021; Accepted July 19, 2021

\section{Cite This Paper in the following Citation Styles}

(a): [1] Alireza Bahrami, Andreas Vall, Asaad Khalaf, "Comparison of Cross-Laminated Timber and Reinforced Concrete Floors with Regard to Load-Bearing Properties," Civil Engineering and Architecture, Vol. 9, No. 5, pp. 1395 1408, 2021. DOI: 10.13189/cea.2021.090513.

(b): Alireza Bahrami, Andreas Vall, Asaad Khalaf (2021). Comparison of Cross-Laminated Timber and Reinforced Concrete Floors with Regard to Load-Bearing Properties. Civil Engineering and Architecture, 9(5), 1395 - 1408. DOI: 10.13189/cea.2021.090513.

Copyright $(2021$ by authors, all rights reserved. Authors agree that this article remains permanently open access under the terms of the Creative Commons Attribution License 4.0 International License

\begin{abstract}
Floors of a building with the relatively new and environmentally sustainable structural material as cross-laminated timber (CLT) and traditional reinforced concrete (RC) are compared in this paper with regard to their load-bearing properties. StruSoft FEM-Design software is utilised to model, analyse and design an existing building using the CLT and RC floors. The building has three stories with a penthouse on the top floor. Modelling, analysis and design of the building can be summarised into five main steps. In step 1 , the building with the RC floors is modelled, analysed and designed according to the geometries and specifications of the building. The RC floors of the building are then changed to the CLT floors with the similar thickness and the function of the building is checked for tensile and compressive stresses, utilisation ratio and deflection in step 2. Step 3 involves checking what reinforcing is required for the CLT floors to be approved with about the same thickness as the RC floors. In step 4, it is controlled whether a larger thickness of the CLT floors without reinforcing can withstand the identical conditions of the RC floors. From the obtained results, effects of thickness of the CLT floors and span width are examined. The structural stability of the building with the CLT and RC floors is controlled in step 5 . Further, the CLT and RC floors of the building are compared in terms of their stresses, utilisation ratios and weights. The results of this paper demonstrate advantages of using the CLT floors. The CLT floors show good
\end{abstract}

strength properties compared with their low weights. It is uncovered that the building with both of the CLT and RC floors is stable. Obtained results of the building with the CLT and RC floors from the StruSoft FEM-Design software are compared with those from calculations based on Eurocode 2 and Eurocode 5, which reveal good agreements with each other regarding their accuracy.

Keywords Cross-Laminated Timber Floor, Reinforced Concrete Floor, Tensile and Compressive Stresses, Utilisation Ratio, Weight, Structural Stability

\section{Introduction}

As the population in Sweden increases, high demands are placed on the production of new buildings and in particular housing. At the same time, as the need for housing and construction is getting larger in parts of the country, it has been found that the carbon dioxide in the atmosphere coming from the construction industry is significant. Thus, stronger measures should be taken to keep the emissions of the construction industry down in order to obtain environmental quality objectives which include a good built environment.

Concrete is a well-established material with good strength properties which has been used in the 
construction of multi-storey buildings, however, a lot of energy is required during its production. On the other hand, a large part of the greenhouse gas emissions comes from the concrete production. But, wood is an environmentally friendly material, whilst, concrete has had a larger market share than that of wood for a long time since wood has mostly been used for lightweight structures such as single-family houses and decorations of larger buildings. Recently, innovative manufacturing methods have given wood new properties that enable its increased usability in several areas [1]. Therefore, there is a great interest in replacing concrete with wood.

In the mid-1960s, the introduction of a novel wood-based product as engineered wood product (EWP) re-emerged the interest in timber structures. After subsequent development incentives, a new composite product as cross-laminated timber (CLT) was introduced in the mid-1990s. CLT is made up of boards or lamellae that are placed crosswise in several layers. The neighbouring boards are most often glued at an angle of $90^{\circ}$ to one another. The thickness of the boards is mostly between $20-60 \mathrm{~mm}$ and the number of layers differs between different manufacturers, but usually $3,5,7$ or more odd layers of boards are used. This is because it is desired to have the highest strength of the material in the main bearing direction, which for wood is along the fibres for both compression and tension. This multi-layered and optimised CLT provides such in-plane and out-of-plane load-bearing capacity that it can be applied as floor panels in the structures [2].

In the last two decades, there has been a development in Swedish structures so that CLT has become increasingly prominent as a structural material mainly due to its strength properties and also its environmental benefits.

CLT panels and floors have been investigated in research projects throughout the world [3-16]. Whereas, CLT and traditional reinforced concrete (RC) floors of an existing building are examined with respect to their load-bearing properties in the current research. Modelling, analysis and design of the building are carried out employing the StruSoft FEM-Design software. Effects of the thickness of the CLT floors and span width are evaluated. Control of the structural stability of the building with the CLT and RC floors is also done.
Moreover, stresses, utilisation ratios and weights of the CLT and RC floors of the building are compared. Comparison is made between the obtained results from the numerical modelling and those from the calculations following Eurocode 2 (EC2) [17] and Eurocode 5 (EC5) [18] for the building having the CLT and RC floors.

\section{Methodology}

An existing building was used as a reference building on which this study was conducted. The methodology of the study is presented in the following.

\subsection{Reference Building}

Figure 1 shows the three-dimensional (3D) plan of the reference building which was taken from the consulting company BTKon. In accordance with the figure, the building has two wings, from which one wing was considered for the investigation in the current study, as shown in Figures 2-4. The red line in Figure 2 illustrates the assumed wall that divides the building. Figure 5 demonstrates the assembly drawing which was utilised to achieve sizes of the floor elements.

\subsection{Finite Element Method}

StruSoft FEM-Design software was employed in the current research to model, analyse and design the reference building. It is an advanced modelling software using the finite element method (FEM). The software has been designed for analyses of reinforced concrete, steel and wood structures, and is adapted to Eurocodes. The Swedish national annex of Eurocode can be used in the software as well. In the software, all parts of the structures such as beams, columns, braces, floors, supports, etc., can be modelled. Loads such as snow, wind and imposed loads are placed based on their geographical locations. Load combinations are generated. Mesh is generated automatically and its mesh size is refined around layouts and connections for increasing accuracy. This can also be set manually. 


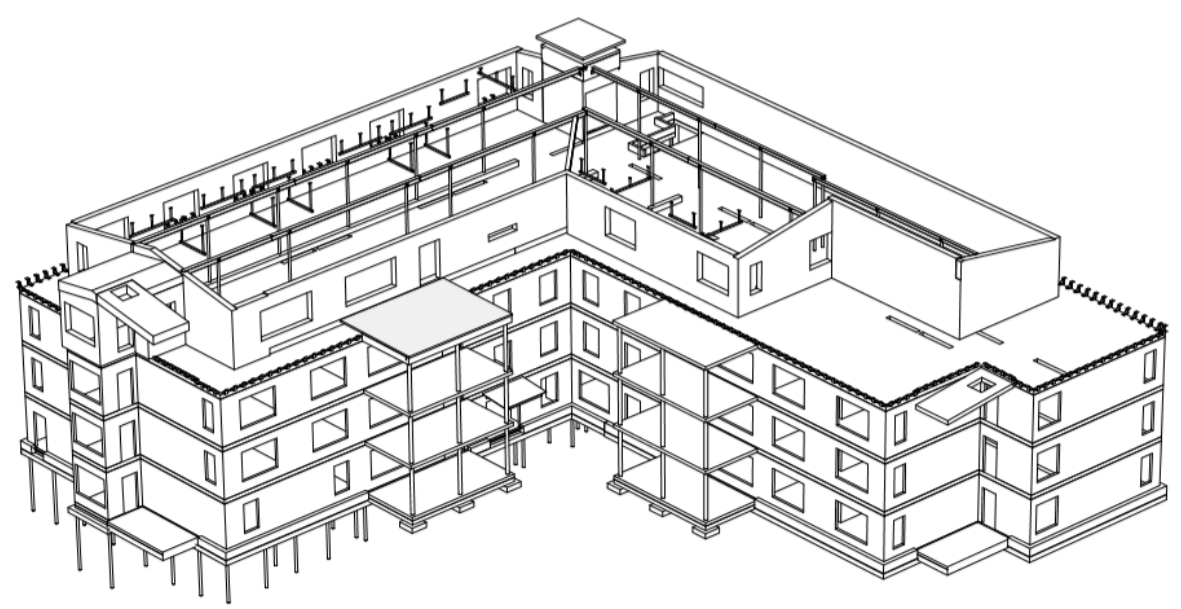

Figure 1. Reference building in 3D

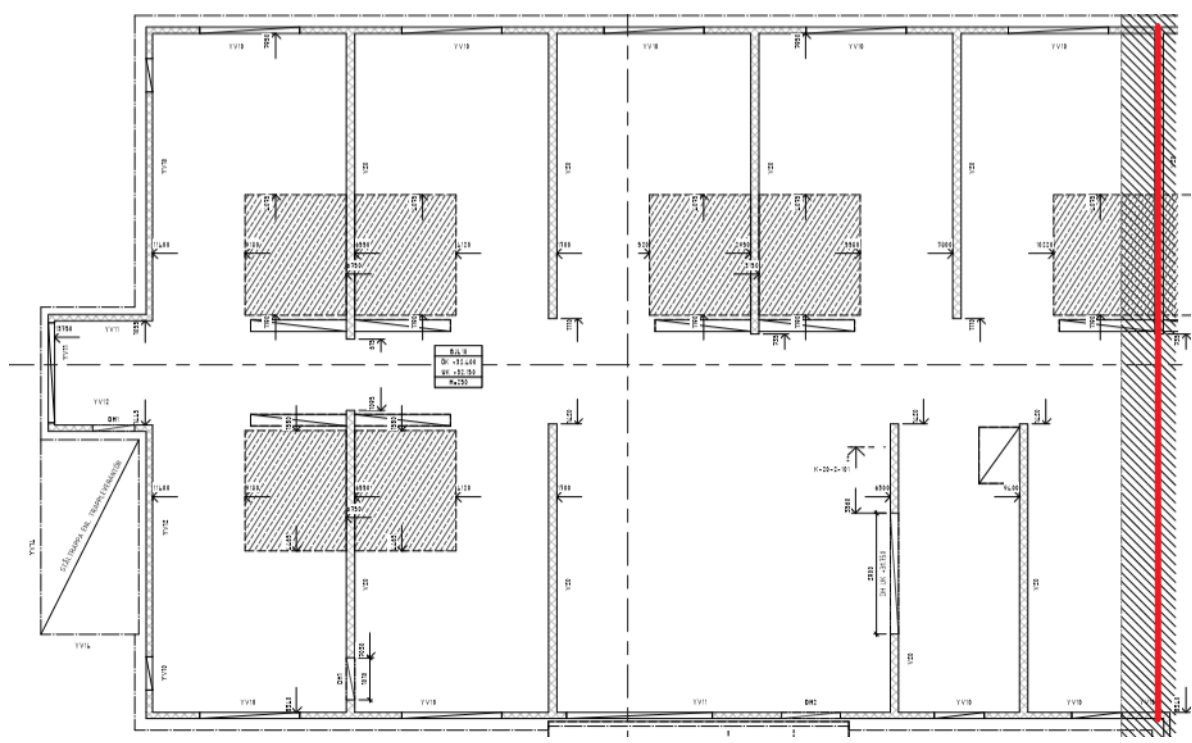

Figure 2. Plan 1

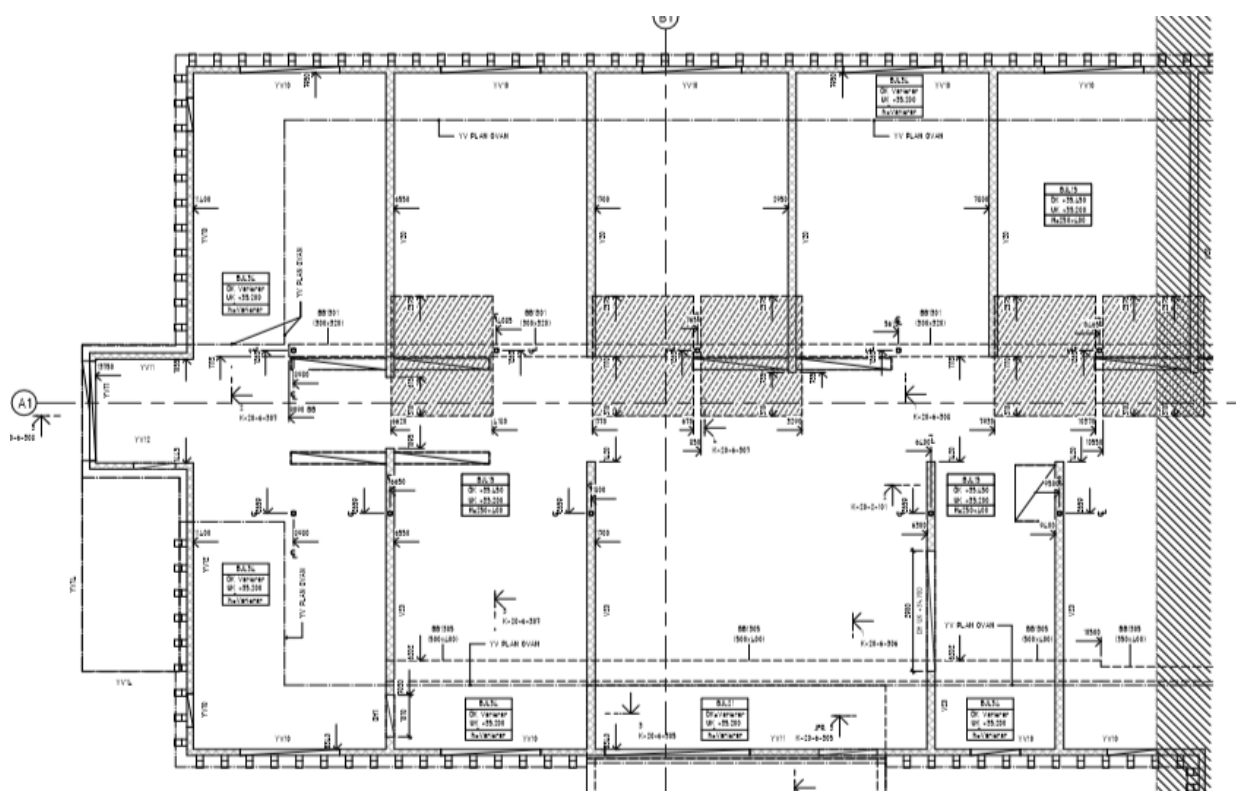

Figure 3. Plan 2 


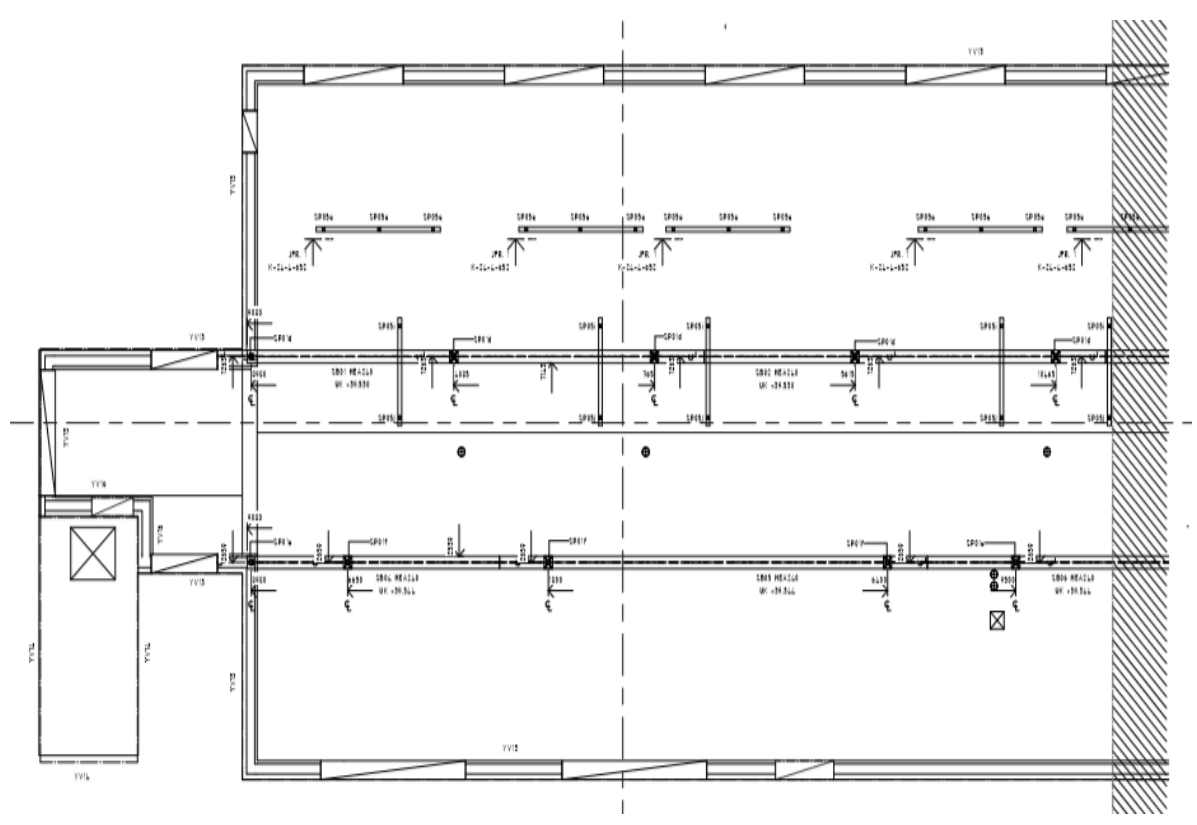

Figure 4. Plan 3 (Roof)

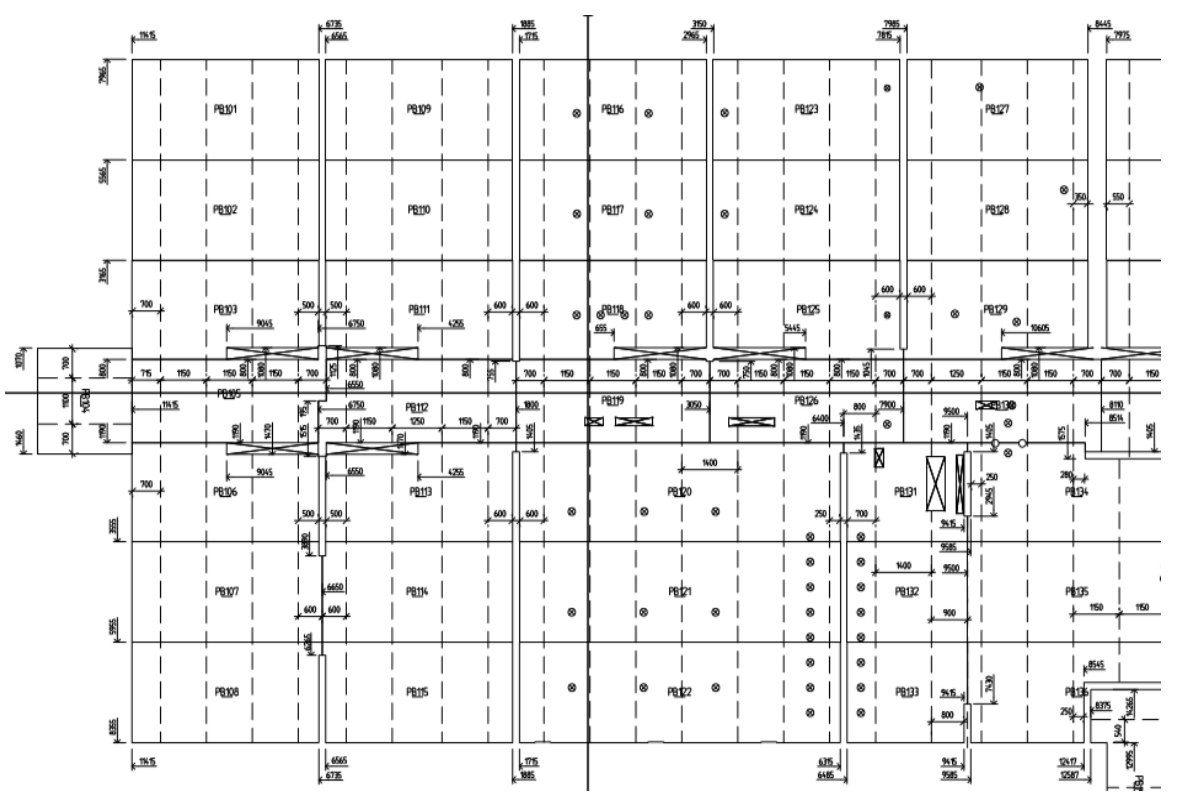

Figure 5. Assembly drawing of floors

\subsubsection{Building with RC Floors}

In the StruSoft FEM-Design software, the geometry of the reference building was modelled. Supports were considered using the line support group, which took rotations and forces in three dimensions into account. Load-bearing exterior $\mathrm{RC}$ walls were modelled with the thickness of $150 \mathrm{~mm}$ according to the geometry of the building with concrete $\mathrm{C} 30 / 37$, the creep ratio of 2.8 and the shrinkage ratio of $0.4 \%$ following the national annex of EC2. Load-bearing interior RC walls had $200 \mathrm{~mm}$ thickness with concrete C30/37. Dimensions of openings in the walls in the form of windows and doors as well as the geometry of the extended penthouse were considered on the basis of the building drawings. The floors were modelled with dimensions in accordance with the reference building too. Intermediate floors had a thickness of $250 \mathrm{~mm}$ and consisted of flat RC slabs. When designing $\mathrm{RC}$, the software applies reinforcements where they make the greatest use with regard to the choices such as possible steel reinforcement, covering layers and spacing. Reinforcement can be checked, among other issues, against deflection and cracking. The penthouse of the building consisted of a lightweight structure which was modelled with walls of structural timber C24 having struts with the centroid space of $600 \mathrm{~mm}$. Interior load-bearing horizontal beams of the penthouse were 
considered as HEA 240, which rested on vertical VKR $100 \times 100 \times 10$ based on the reference building. Figures 6-9 indicate the modelled facades. The utilised loads and weights of the materials were obtained from BTKon. Table 1 lists the considered loads.

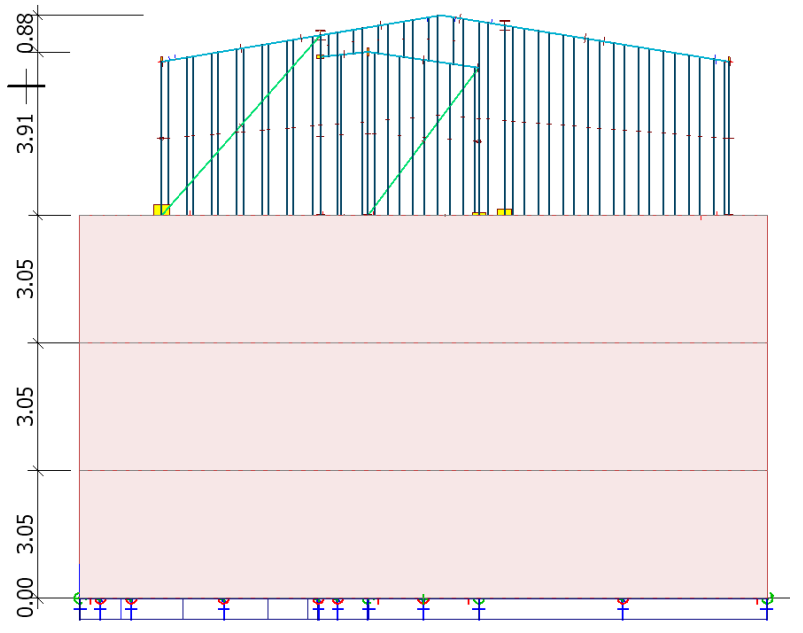

Figure 6. Facade towards X- (unit: $\mathrm{m}$ )

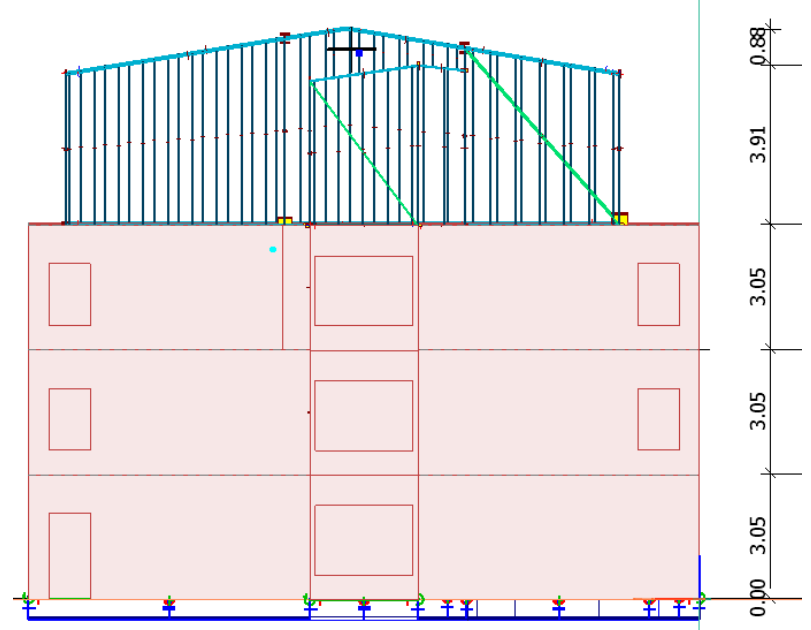

Figure 7. Facade towards $\mathrm{X}+($ unit: $\mathrm{m})$

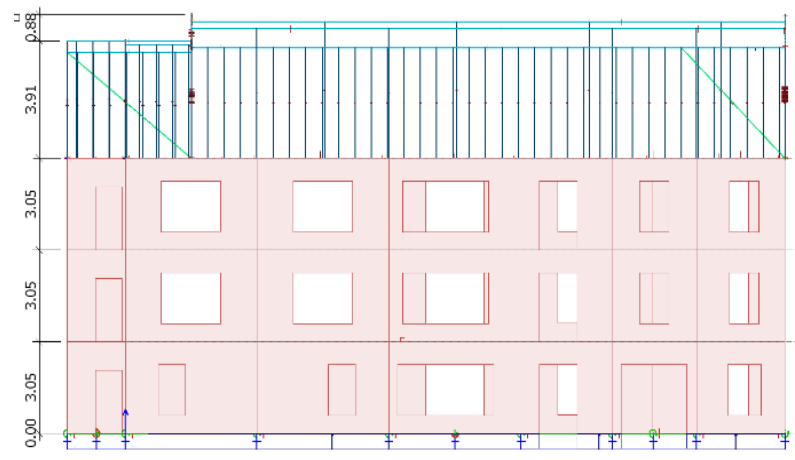

Figure 8. Facade towards $\mathrm{Y}+$ (unit: $\mathrm{m}$ )

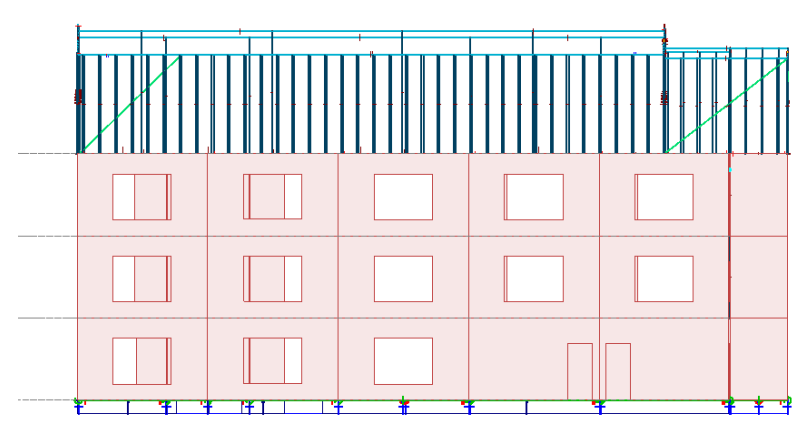

Figure 9. Facade towards Y-

Table 1. Loads used in modelling

\begin{tabular}{|c|c|}
\hline Load type & Load consideration \\
\hline Roof & $1 \mathrm{kN} / \mathrm{m}^{2}$ \\
\hline Imposed load & $2 \mathrm{kN} / \mathrm{m}^{2}$ \\
\hline Roof service & $0.4 \mathrm{kN} / \mathrm{m}^{2}$ \\
\hline Snow load & $2 \mathrm{kN} / \mathrm{m}^{2}$ (zone load) \\
\hline Wind load & $24 \mathrm{~m} / \mathrm{s}$ (reference wind speed) \\
\hline
\end{tabular}

The next step was the loads as dead, imposed, snow and wind that were applied to the building. The load cases were grouped and their appropriate partial coefficients were selected. Permanent load was allocated to the building's parts and the roof structure. The remaining loads were assumed to be temporary. The surfaces were loaded with the imposed load of $2 \mathrm{kN} / \mathrm{m}^{2}$ which was applied as a distributed load. The snow load of $2 \mathrm{kN} / \mathrm{m}^{2}$ was applied to the roof and roof terraces. The wind load was generated by the wind function of the software having the wind speed of $24 \mathrm{~m} / \mathrm{s}$ and terrain type II, and was then applied to the building. Afterwards, the software varied the current loads into combinations to accomplish the most unfavourable one. A suitable mesh was generated and the analysis was performed having the standard elements with $4 / 3 / 2$ nodes. Figure 10 elaborates the building with the mesh. Finally, the analysis and design of the building's elements were carried out.

\subsubsection{Building with CLT Floors}

There is an option in the software to choose the desired CLT panels from various CLT panels that exist in its library with a lot of dimensions from different manufacturers. A material library developed with the most common suppliers is also available. Setra has a wide range of CLT which is available in the library of the software. When choosing the dimension of CLT flooring in this study, Setra's range for CLT flooring was considered. The CLT module makes it possible to calculate and analyse laminated structures with regard to the orthotropic properties of wood, which enables rotation of the material so that different properties of the material can be taken into account depending on the direction. When changing the floors of the building from RC to CLT, the CLT elements were adopted to be the same size as the flat layers with the widths of $2.4 \mathrm{~m}$ and lengths according to the reference building. Joints of the floors were assumed 
to be simply supported. Other structural elements of the building, the loads, supports and mesh were kept similar to those mentioned in section 2.2.1. The modelled building with the CLT floors is depicted in Figure 11.

\section{Results and Discussions}

The building with RC floors and then CLT floors was analysed. The results were achieved from the analyses, which are presented in the following.

\subsection{Stresses in RC Floors of Building}

Stresses in the RC floors of the building are investigated here. Walls and floors were designed with concrete having reinforcement of $\phi 10 @ 150$ where the software was also allowed to design with the compressive reinforcement if required. To meet the utilisation ratio below $100 \%$, the software was allowed to automatically use other reinforcement dimensions. The utilisation ratios below $100 \%$ could be met. Figures 12-23 display the outputs regarding the distribution of stresses in the RC floors in the $x^{\prime}$ and $y^{\prime}$ directions. $x^{\prime}$-top which is the primary direction of the floors shows compressive stresses in the spans and tensile stresses at the supports. $x^{\prime}$-bottom illustrates tensile stresses of the floors in the spans and compressive stresses at the supports. $y^{\prime}$-top and bottom stresses were calculated as the secondary direction across the floor elements.

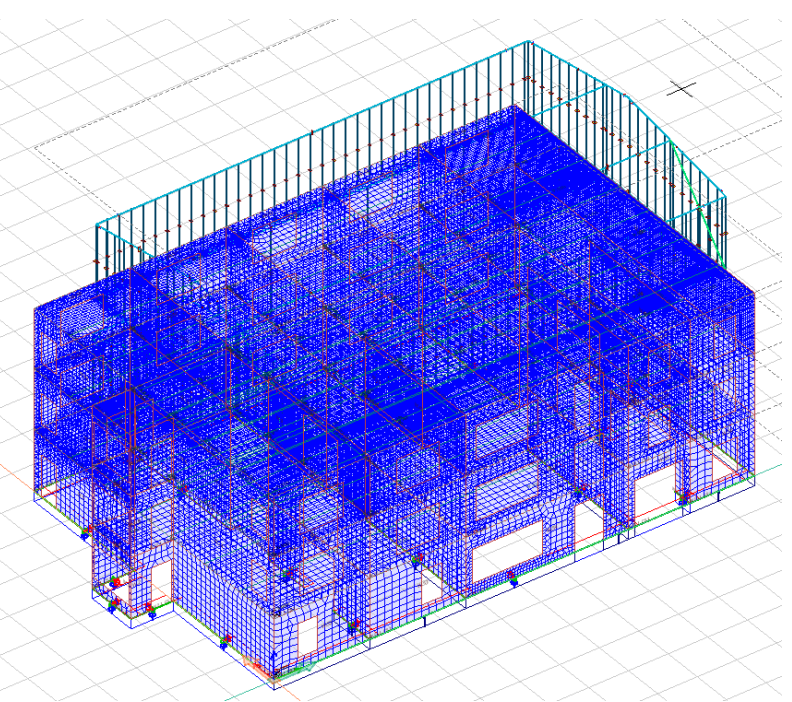

Figure 10. Building with mesh

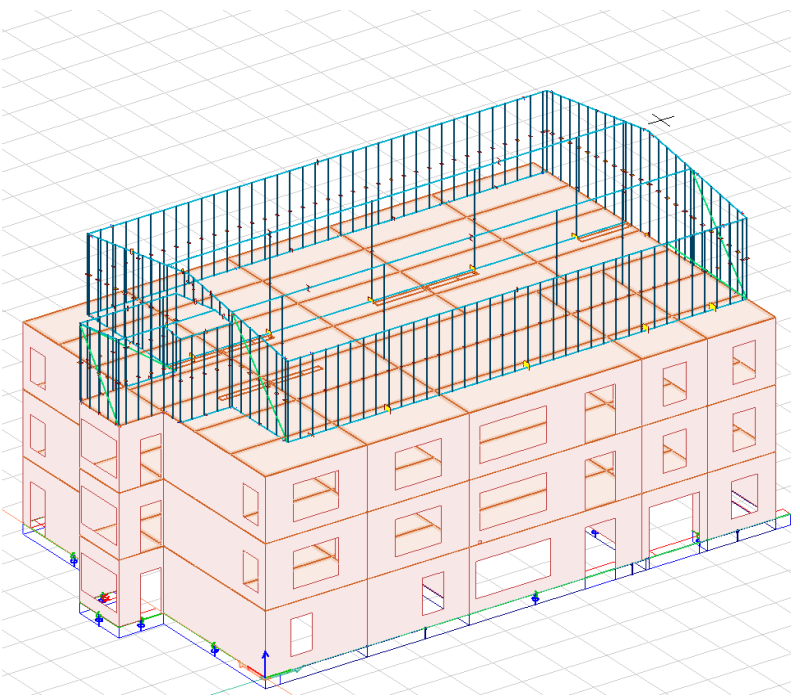

Figure 11. Modelled building with CLT floors

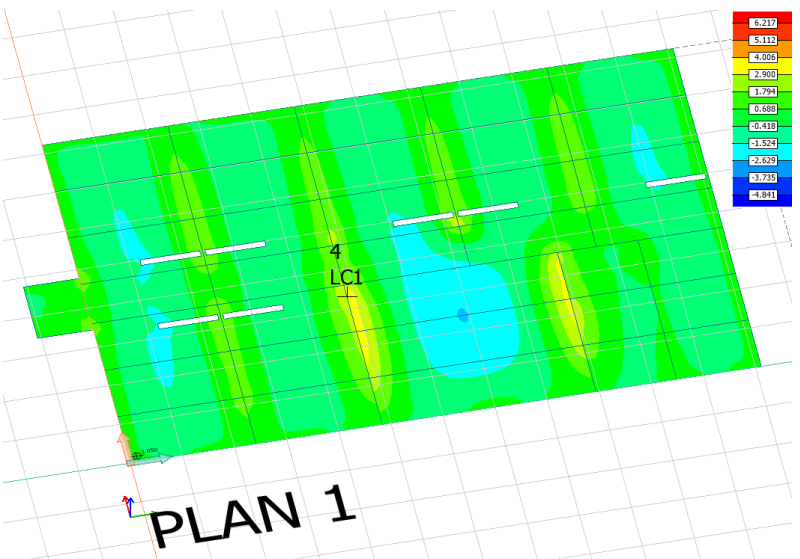

Figure 12. Stress distribution, Sigma $x^{\prime}$, top+

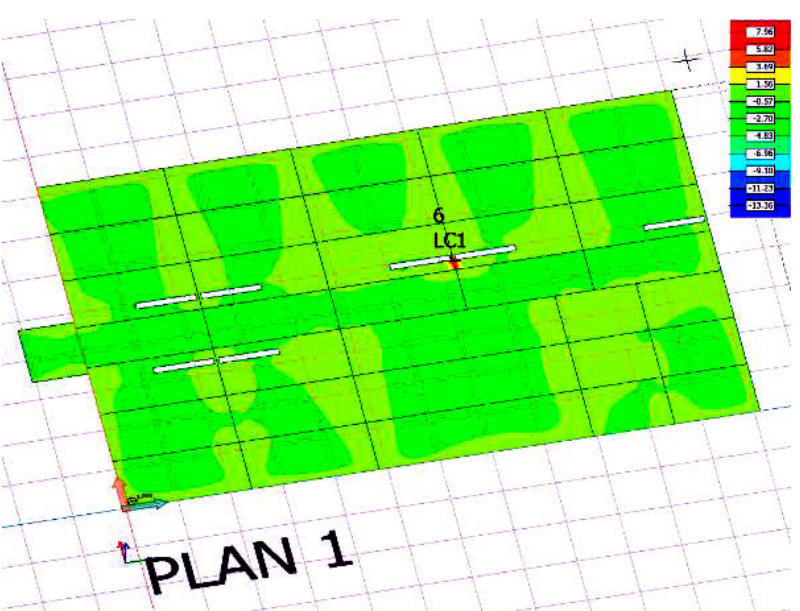

Figure 13. Stress distribution, Sigma $y^{\prime}$, top + 


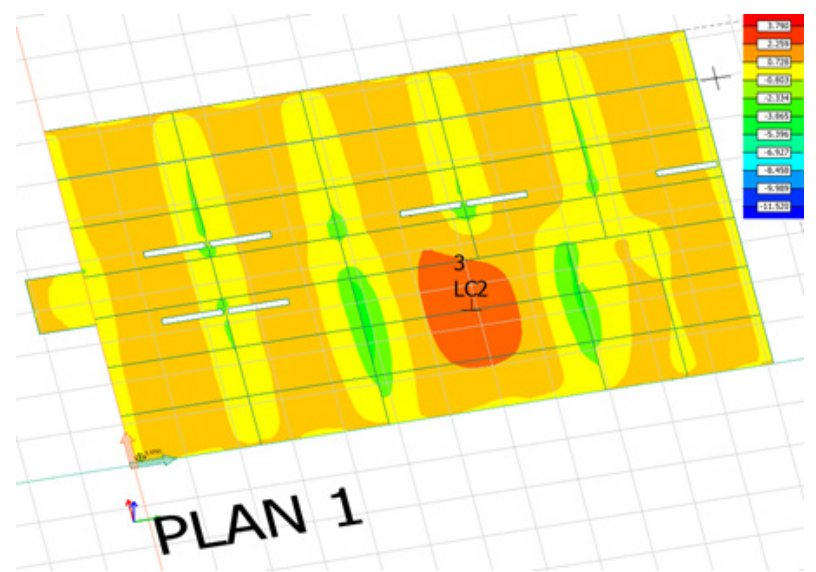

Figure 14. Stress distribution, Sigma $x^{\prime}$, bottom+

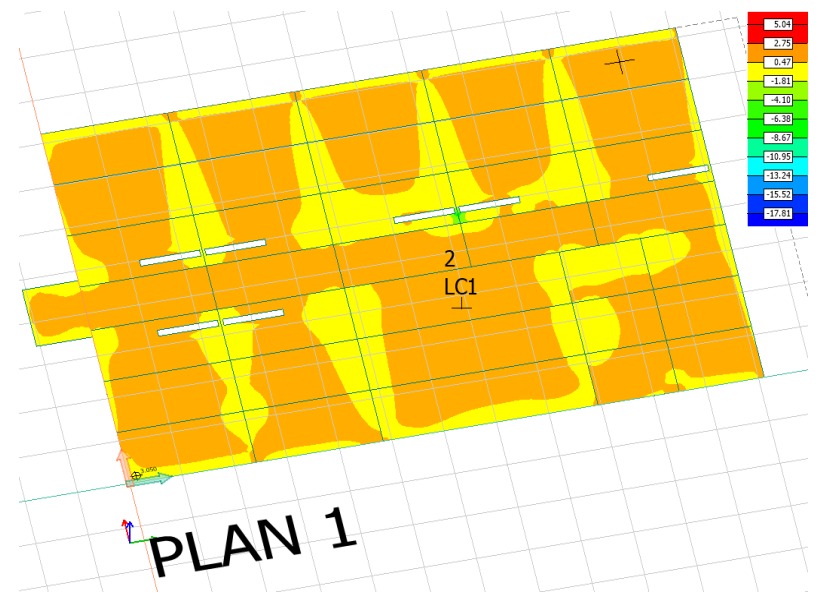

Figure 15. Stress distribution, Sigma y', bottom +

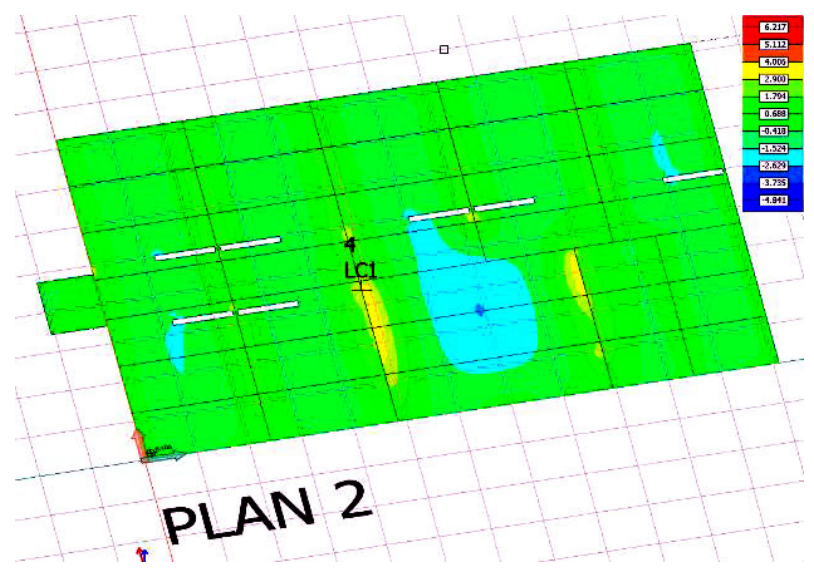

Figure 16. Stress distribution, Sigma $\mathrm{x}^{\prime}$, top +

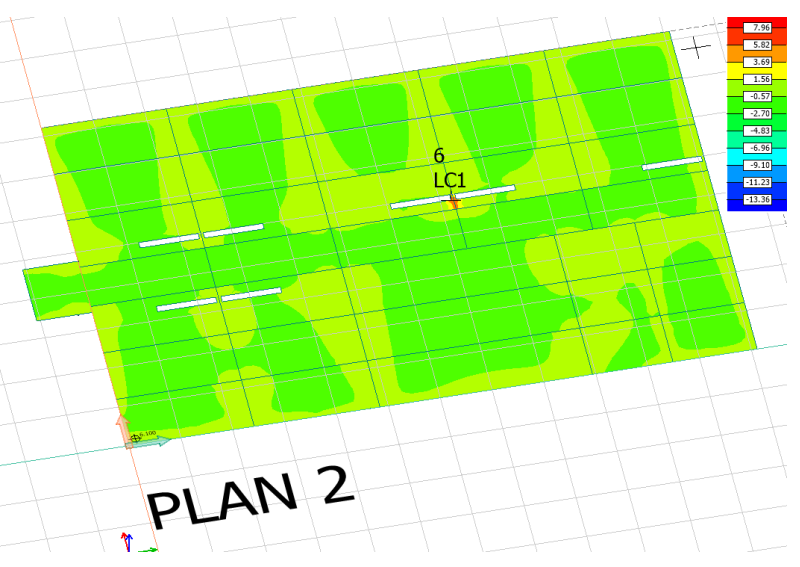

Figure 17. Stress distribution, Sigma $\mathrm{y}^{\prime}$, top +

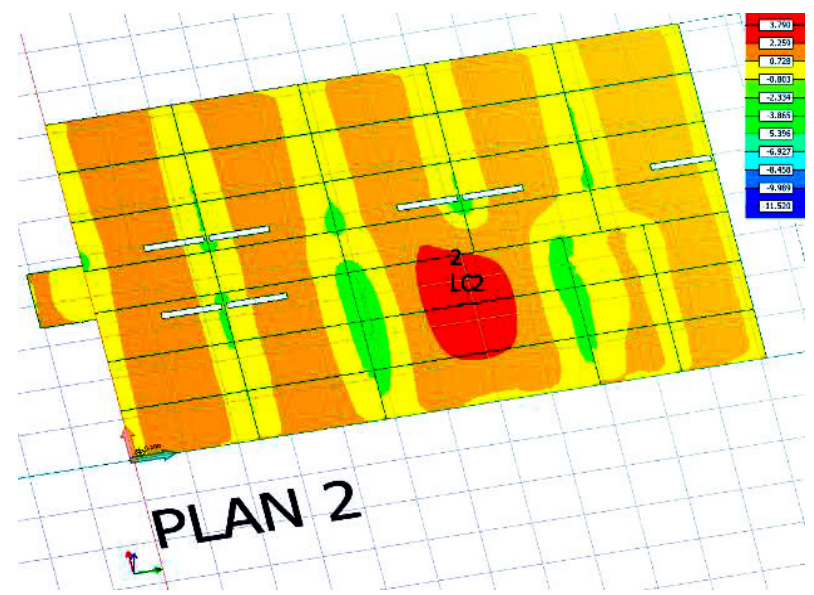

Figure 18. Stress distribution, Sigma $x^{\prime}$, bottom+

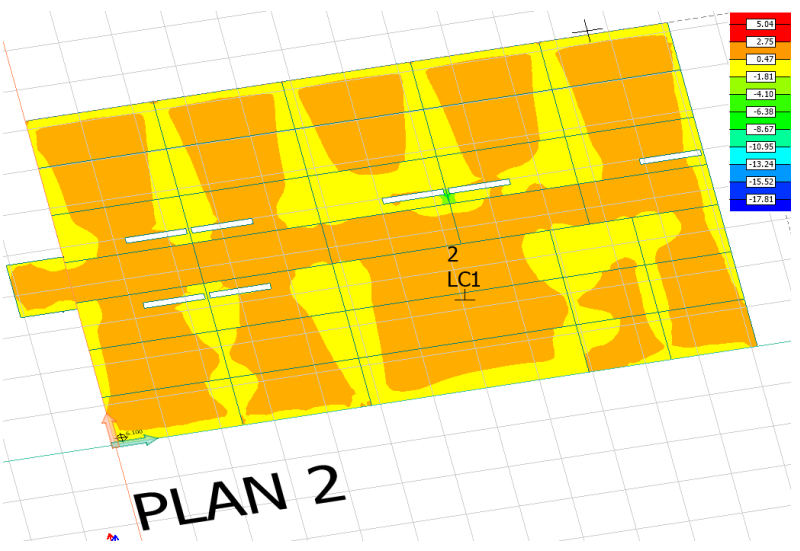

Figure 19. Stress distribution, Sigma y', bottom+ 


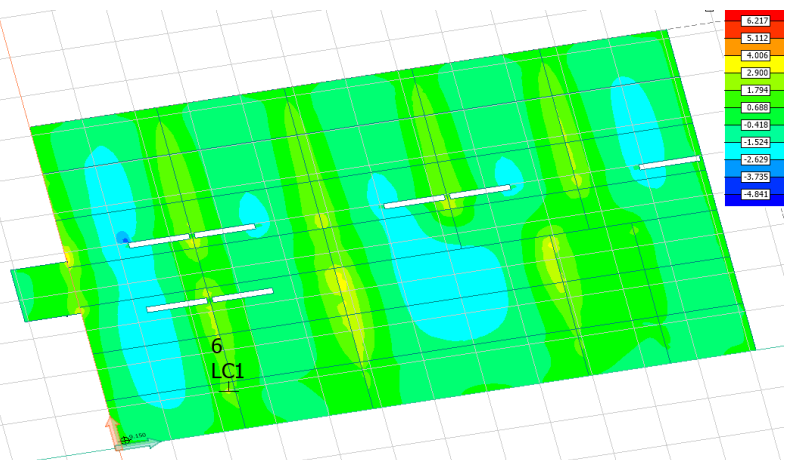

\section{PLAN 3}

Figure 20. Stress distribution, Sigma $x^{\prime}$, top+

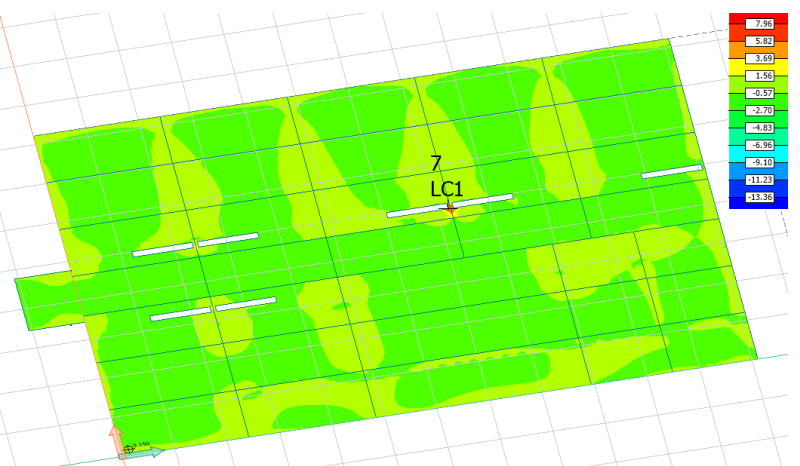

PLAN 3

Figure 21. Stress distribution, Sigma y', top +

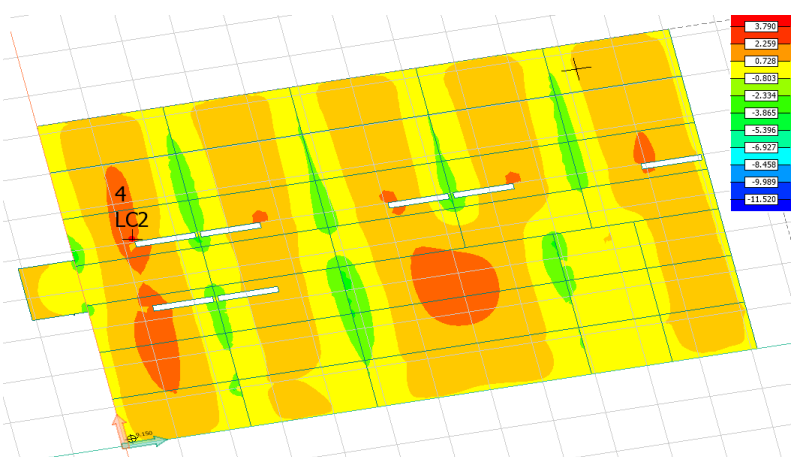

\section{PLAN 3}

Figure 22. Stress distribution, Sigma x', bottom+

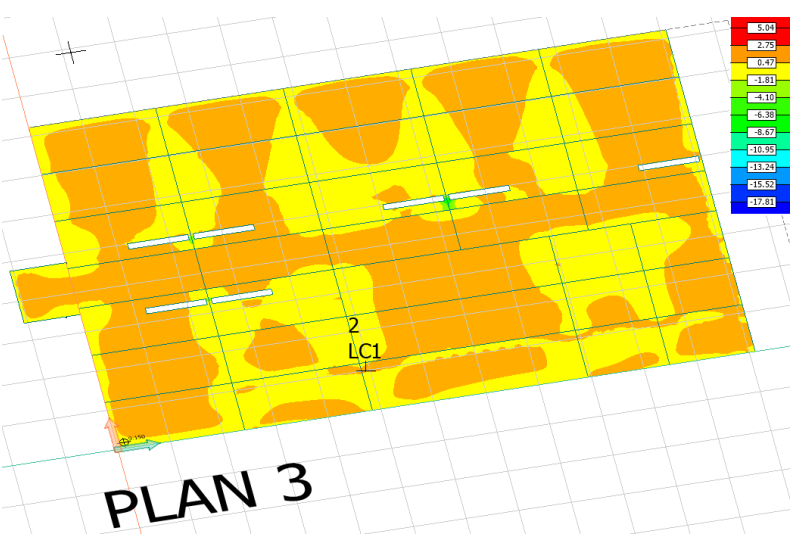

Figure 23. Stress distribution, Sigma y', bottom+

\subsection{Stresses in CLT Floors of Building}

Several attempts were made by using CLT elements with different numbers of layers to obtain the acceptable utilisation ratios. Finally, seven-layer CLT elements with $260 \mathrm{~mm}$ thickness could accomplish acceptable utilisation ratios with a comparable thickness of the RC floor, which were taken as the CLT floors of the building. The typical stresses in the CLT floors of the building are shown in Figures 24-33.

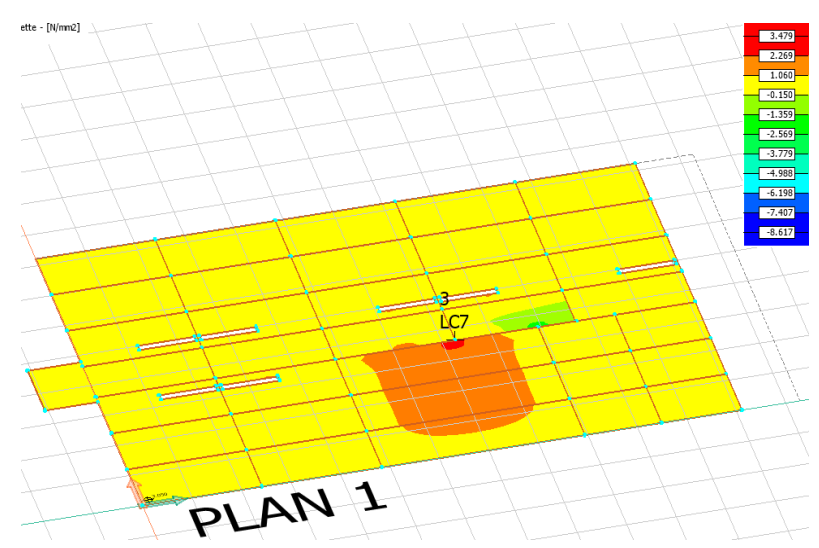

Figure 24. Stress distribution, Sigma $x^{\prime}$, top ${ }^{+}$

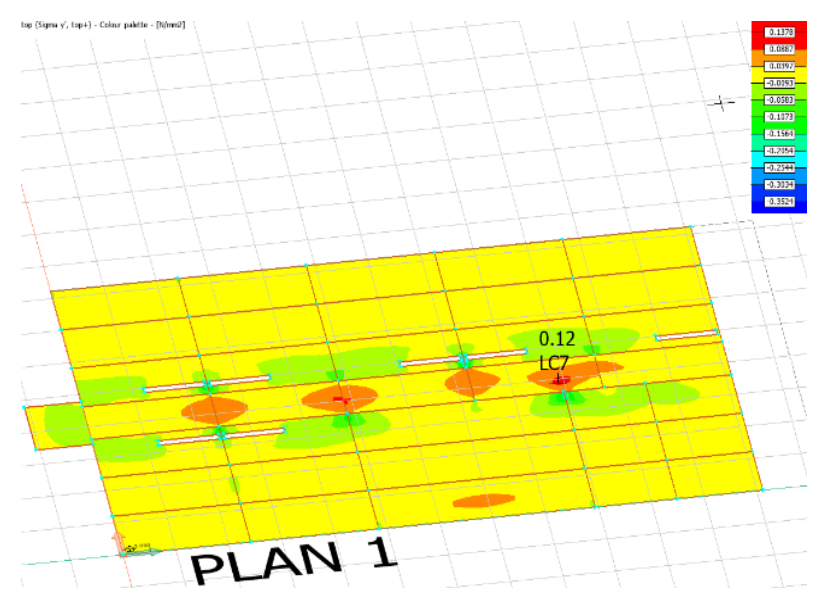

Figure 25. Stress distribution, Sigma y', top+

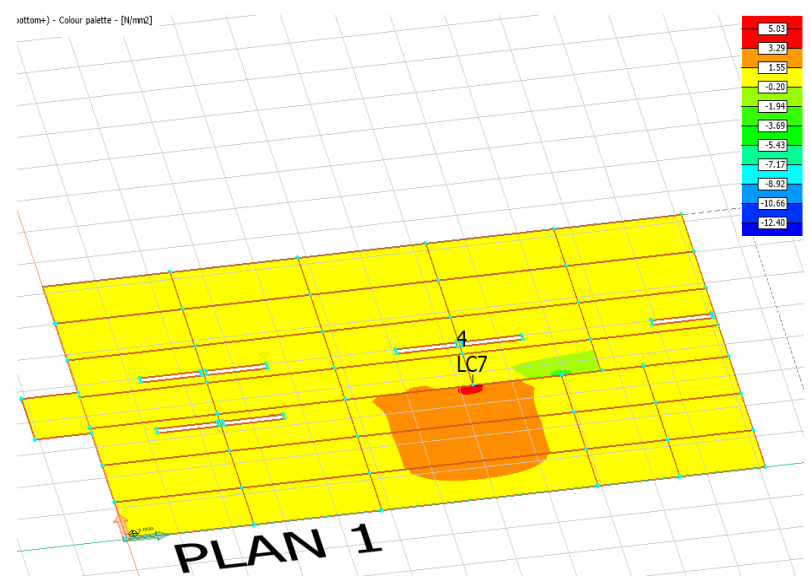

Figure 26. Stress distribution, Sigma x', bottom+ 


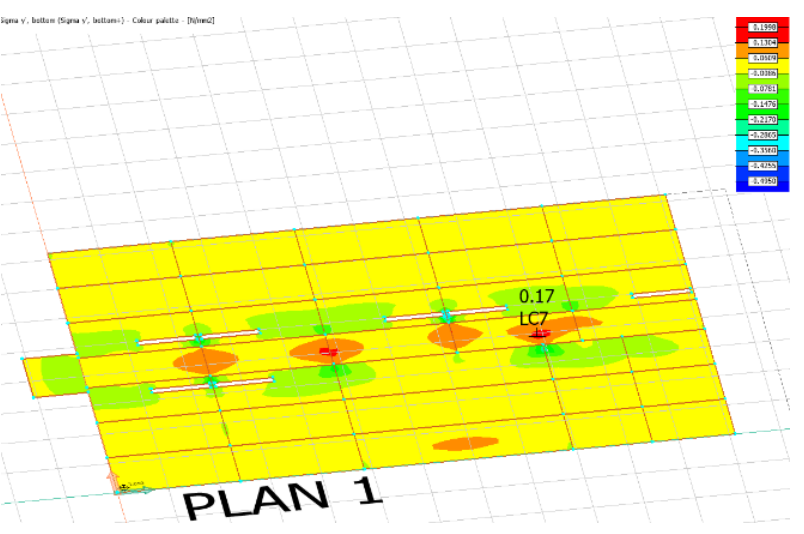

Figure 27. Stress distribution, Sigma y', bottom+

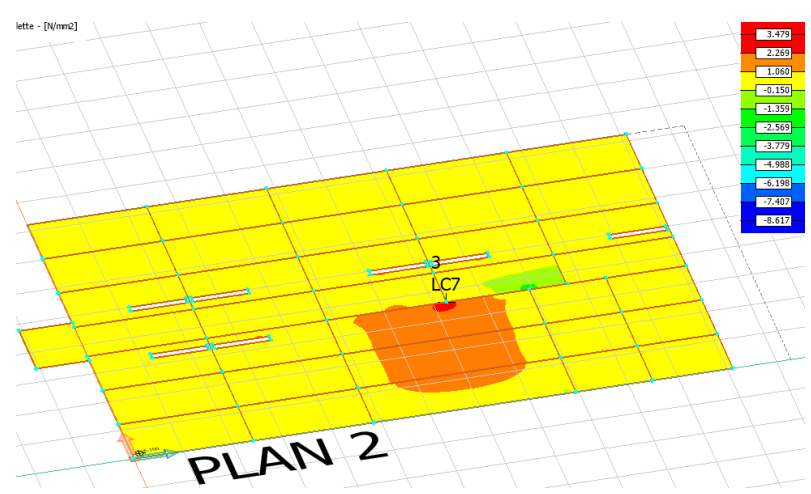

Figure 28. Stress distribution, Sigma $x^{\prime}$, top ${ }^{+}$

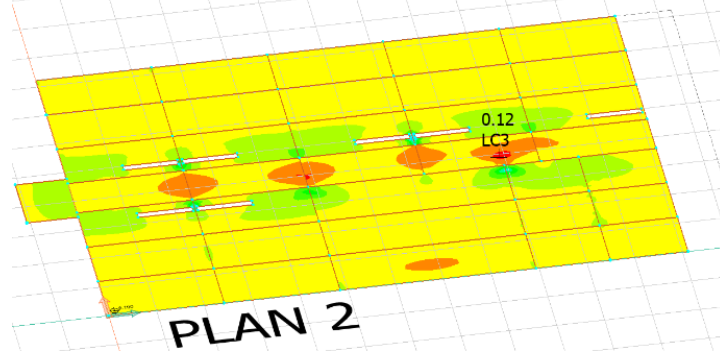

Figure 29. Stress distribution, Sigma $y^{\prime}$, top+

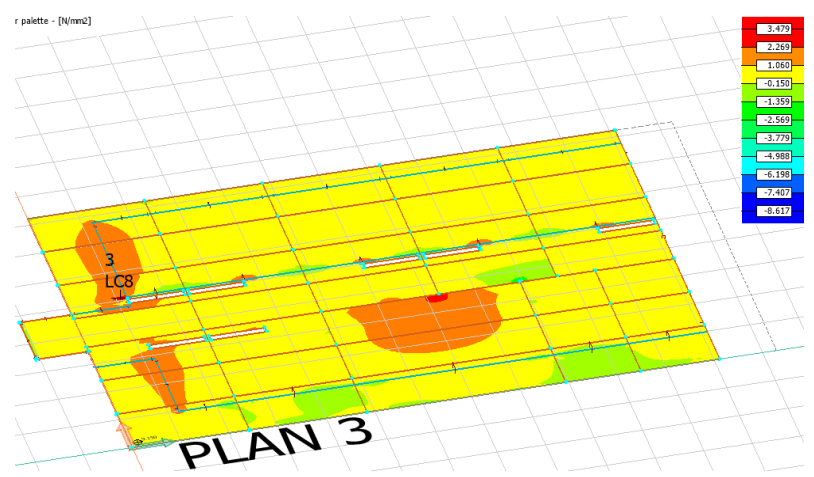

Figure 30. Stress distribution, Sigma $x^{\prime}$, top +

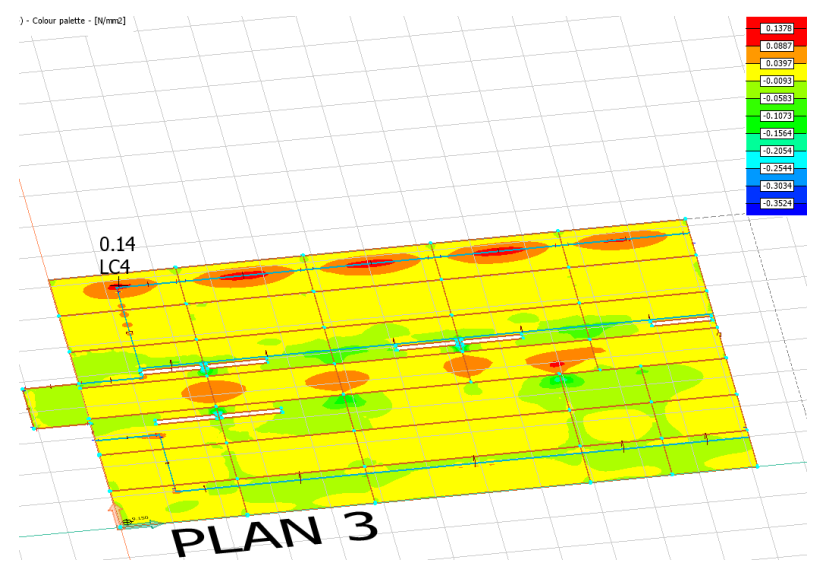

Figure 31. Stress distribution, Sigma $y^{\prime}$, top+

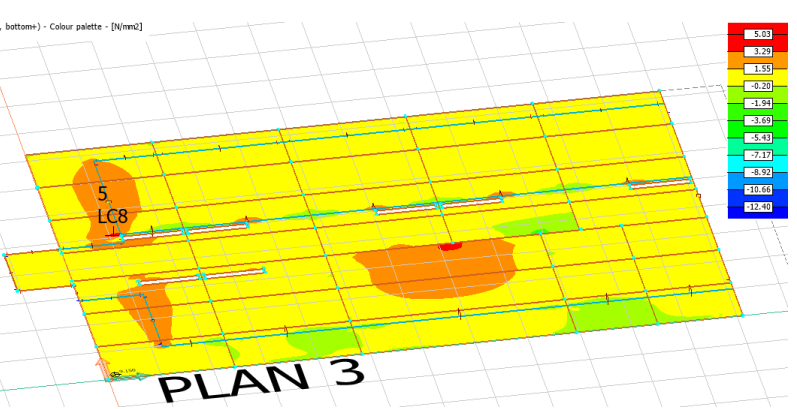

Figure 32. Stress distribution, Sigma $x^{\prime}$, bottom +

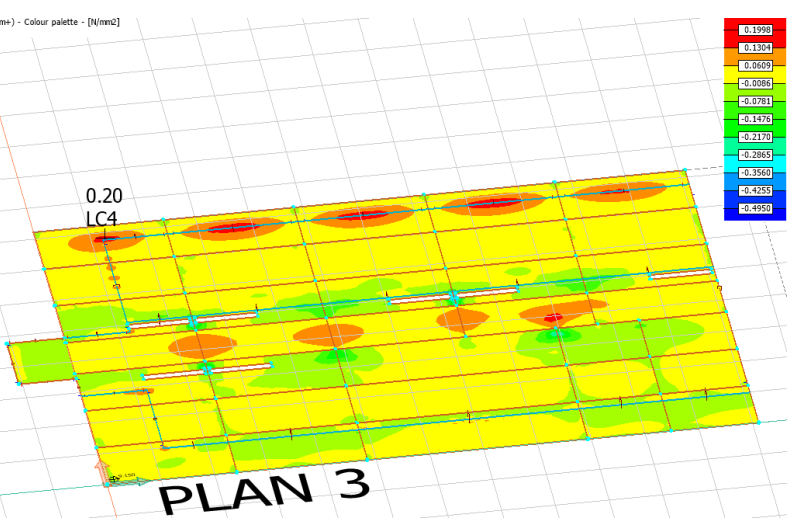

Figure 33. Stress distribution, Sigma $y^{\prime}$, bottom+

\subsection{Utilisation Ratios of RC Floors of Building}

The utilisation ratios of the RC floors of the building were controlled to be below $100 \%$. The obtained utilisation ratios of the floors are illustrated in Figures 34-36 which are below $100 \%$ and consequently acceptable. 


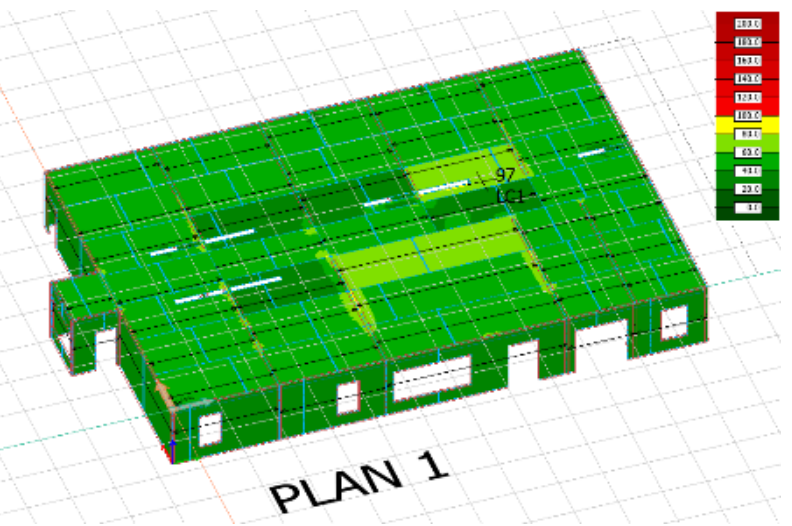

Figure 34. Utilisation ratio of RC floor, $97 \%$

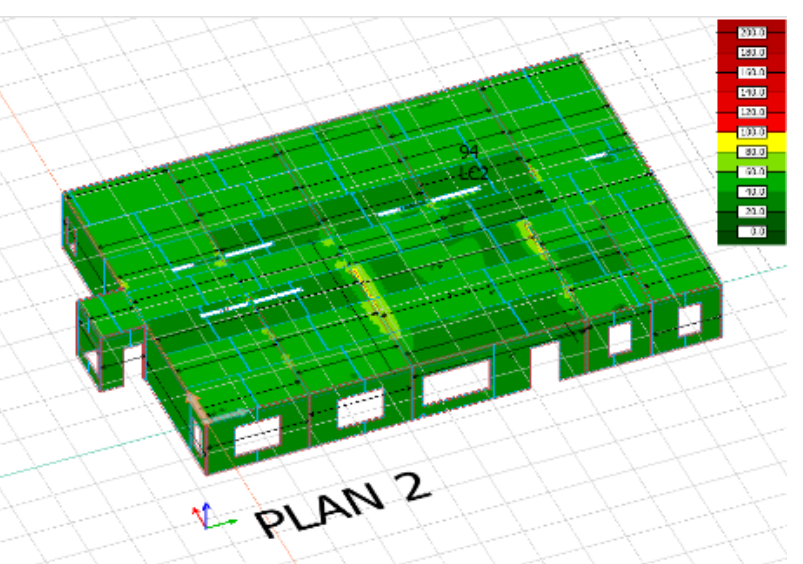

Figure 35. Utilisation ratio of RC floor, $94 \%$

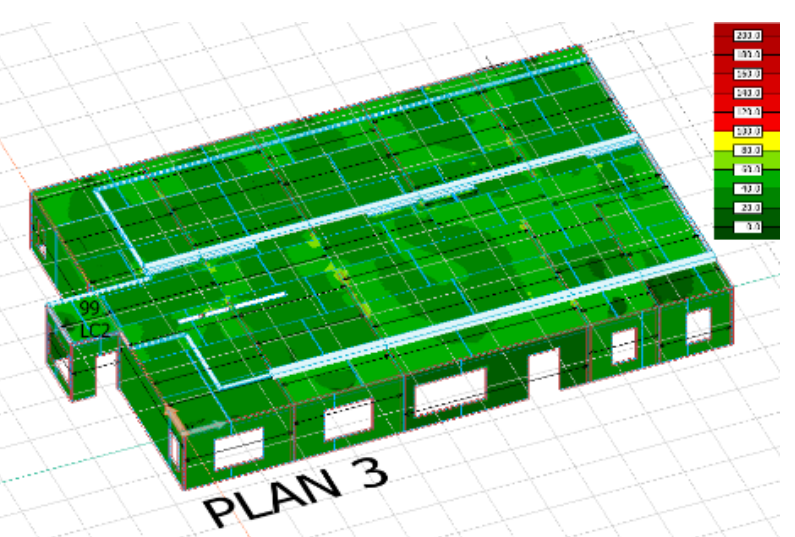

Figure 36. Utilisation ratio of RC floor, $99 \%$

\subsection{Utilisation Ratios of CLT Floors of Building}

The utilisation ratios of the CLT floors for plans 1,2 and 3 of the building were checked that were $124 \%, 123 \%$ and $118 \%$, respectively. Since these utilisation ratios were above $100 \%$, therefore, they were not acceptable which implied that the CLT floors needed to be reinforced to meet the utilisation ratios below $100 \%$.

Figure 37 demonstrates that the utilisation ratio was too high (124\%) between two installation openings. An alternative reinforcing was in the form of a short supporting beam with the dimensions of $\mathrm{b} \times \mathrm{h} \times 1$ as 200 $\mathrm{mm} \times 250 \mathrm{~mm} \times 400 \mathrm{~mm}$, which was tested under the floor of plan 1 according to Figure 38. Then, it was resulted in the utilisation ratio being reduced from $124 \%$ to $92 \%$ (Figure 39).

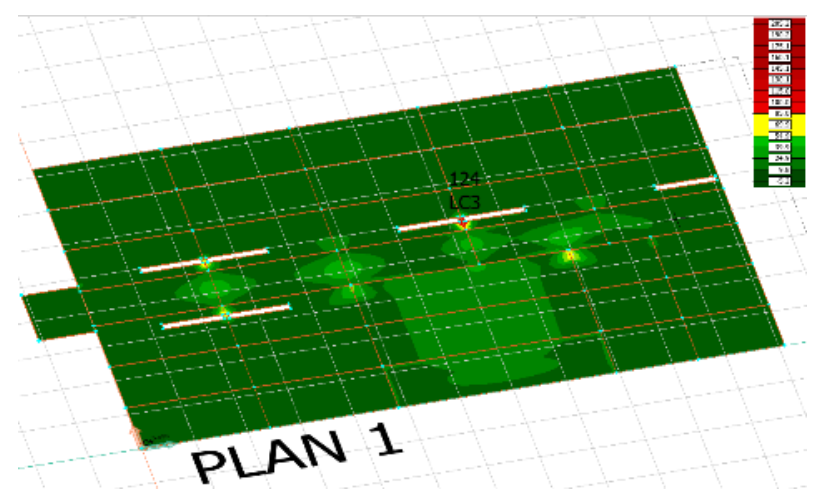

Figure 37. Utilisation ratio of CLT floor before reinforcing, 124\%

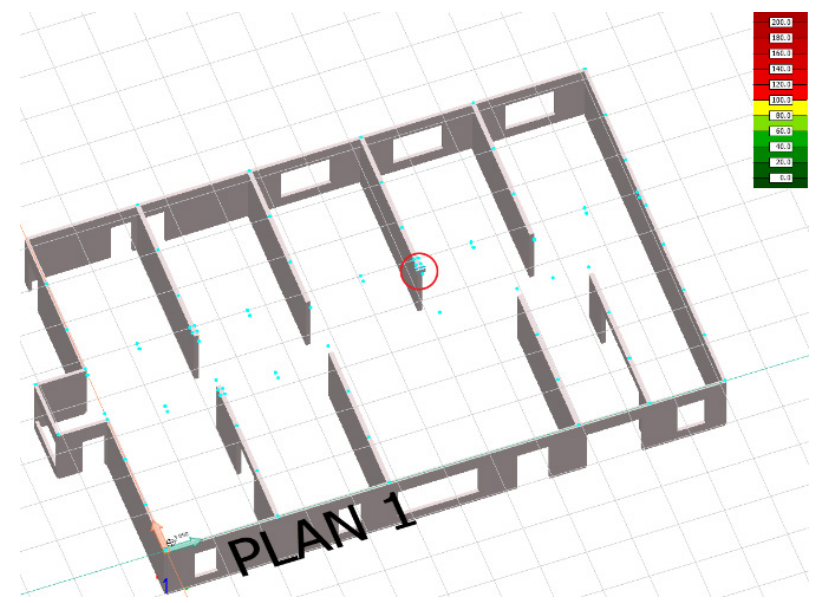

Figure 38. Reinforcing number 1 for CLT floor

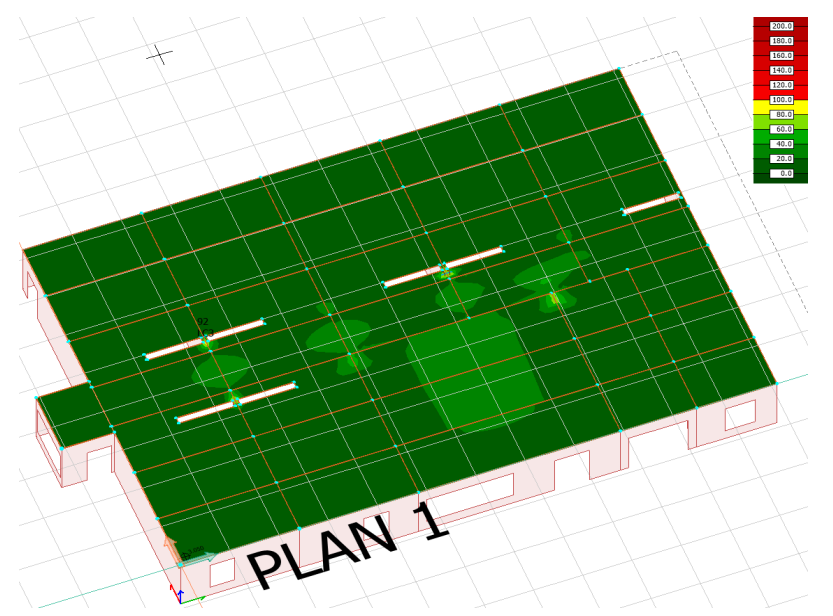

Figure 39. Utilisation ratio of CLT floor after reinforcing, $92 \%$

Also, the utilisation ratio of the floor of plan 2 was $123 \%$, as can be seen from Figure 40. The floor was supplemented with a supporting beam (number 2) and the same short supporting beam (number 1) which was 
explained for plan 1. These reinforcing solutions can be observed from Figure 41. Afterwards, the floor could achieve the utilisation ratio of $94 \%$ in accordance with Figure 42.

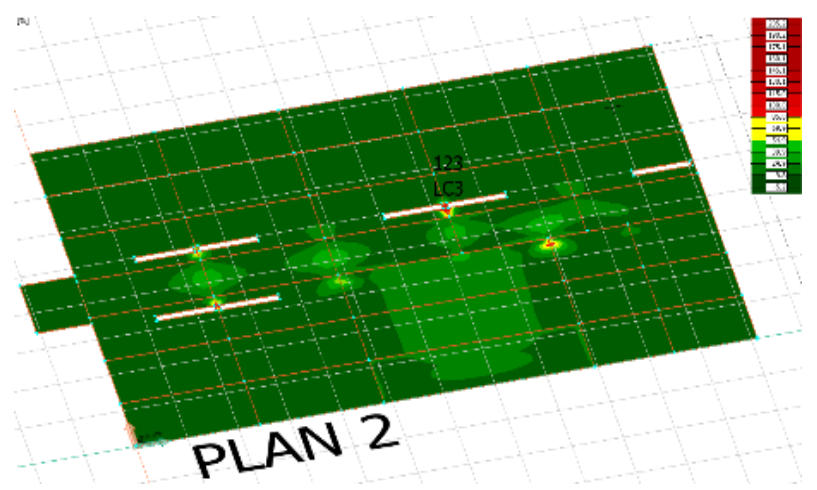

Figure 40. Utilisation ratio of CLT floor before reinforcing, 123\%

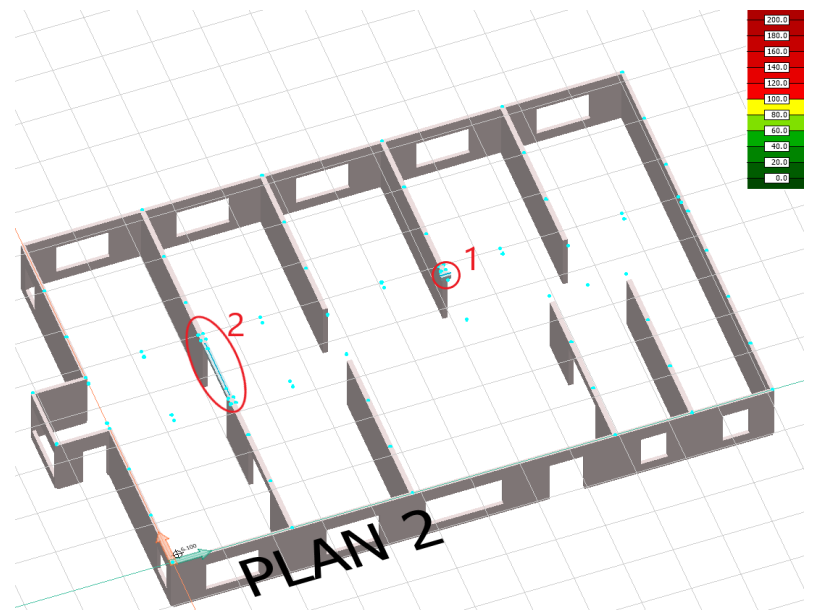

Figure 41. Reinforcing numbers 1 and 2 for CLT floor

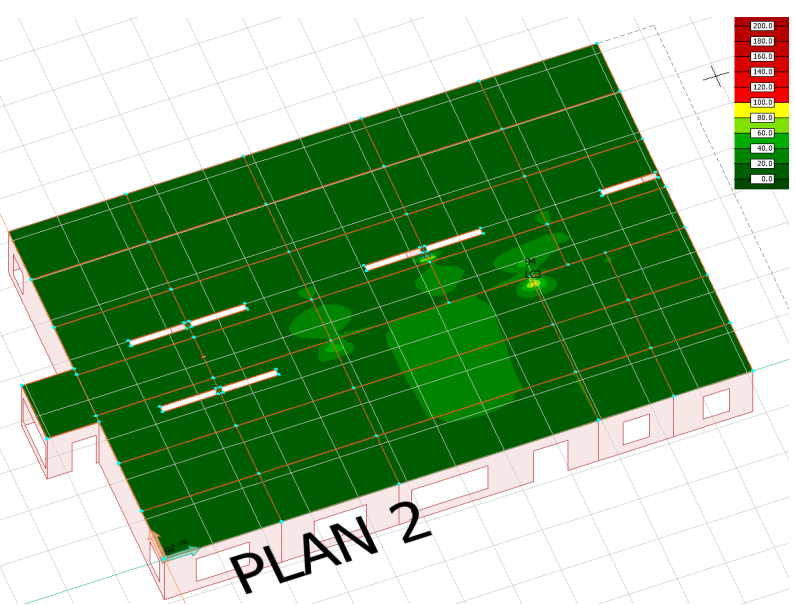

Figure 42. Utilisation ratio of CLT floor after reinforcing, 94\%

Moreover, the utilisation ratio of the floor of plan 3 was $118 \%$ (Figure 43). The adopted reinforcing solutions for this floor are indicated in Figure 44. The reason for reinforcing number 3 was due to the applied load from the penthouse. Figure 45 clarifies that the utilisation ratio of the floor was $99 \%$ after reinforcing.

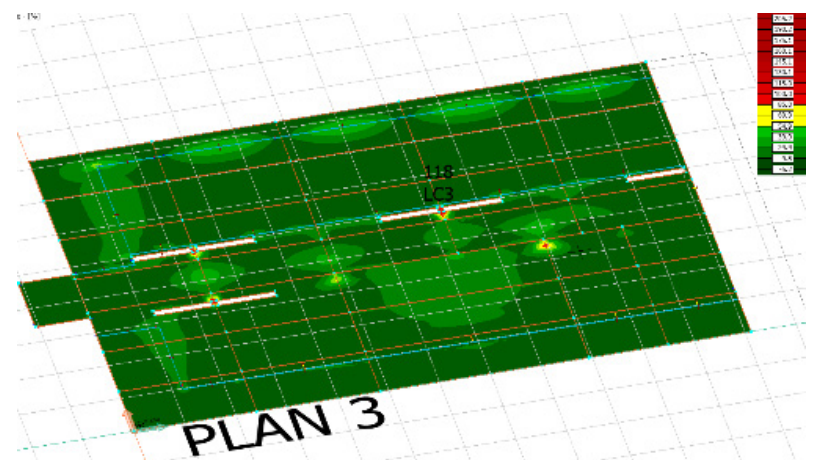

Figure 43. Utilisation ratio of CLT floor before reinforcing, 118\%

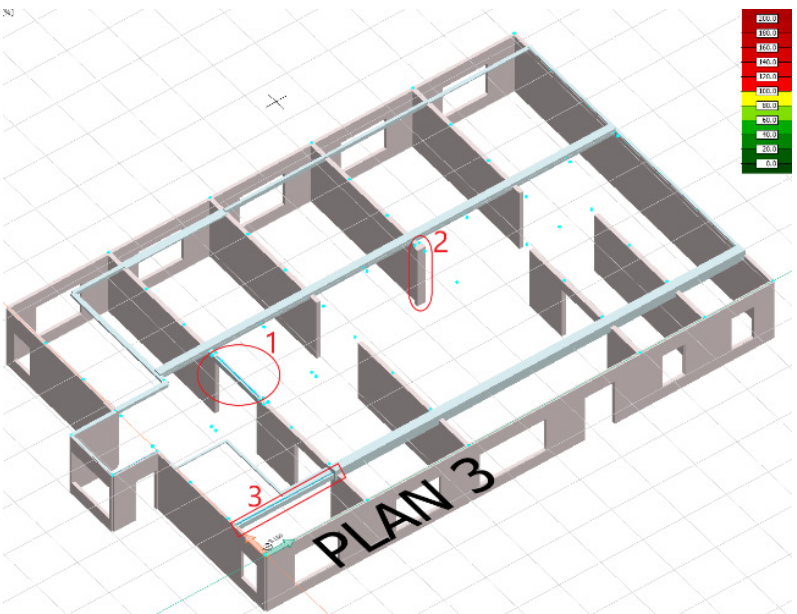

Figure 44. Reinforcing numbers 1, 2 and 3 for CLT floor

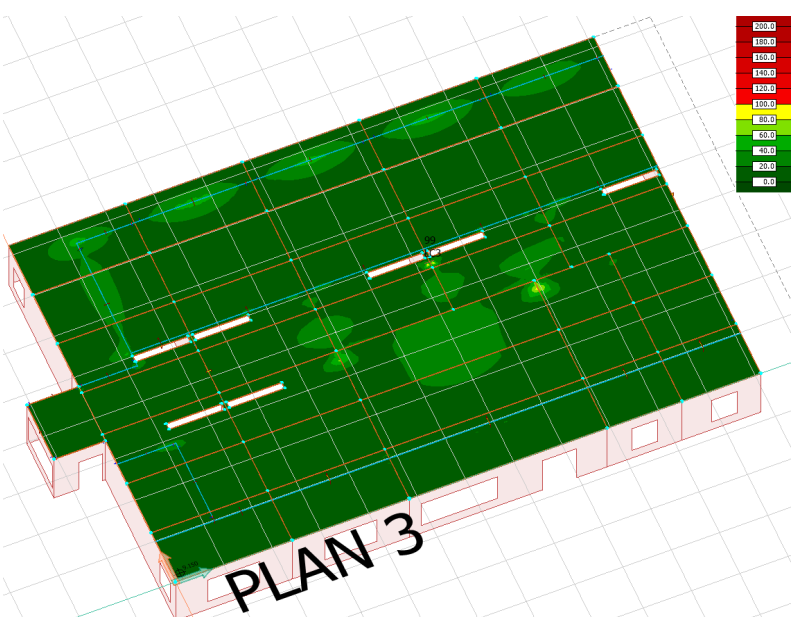

Figure 45. Utilisation ratio of CLT floor after reinforcing, 99\%

\subsection{Effects of Thickness of CLT Floors and Span Width}

The effect of thickness of the CLT floor was also evaluated. The thickness of the CLT floor was changed using Setra Group's material library from the software, until the floor elements had the utilisation ratios below $100 \%$. Existing dimensions are $270 \mathrm{~mm}-300 \mathrm{~mm}$. However, the thickness of $280 \mathrm{~mm}$ had the utilisation ratio of $114 \%$ for one of the floors. The thickness was 
changed for more steps to $300 \mathrm{~mm}$ which resulted in the maximum utilisation ratio of $99 \%$. Therefore, the CLT floors with the thickness of $300 \mathrm{~mm}$ could lead to the acceptable utilisation ratios without the need for any reinforcing.

Spans between $7.7 \mathrm{~m}$ to $10 \mathrm{~m}$ were examined with respect to their deflections in quasi-permanent load combinations. The controlled floors were made of RC and CLT with the thicknesses of $250 \mathrm{~mm}$ and $300 \mathrm{~mm}$, respectively. The CLT floors tended to deflect more than the RC floors. It was due to their difference in the material's properties such as density and bending stiffness based on moment of inertia and modulus of elasticity. Concrete has a higher bending stiffness than CLT, which can be the reason why the CLT floors had larger deflections. On the plans, walls that carried the loads from the longest floor elements were moved. A total of three elements were affected with $8.2 \mathrm{~m}$ in the ordinary design (Figure 46). The wall that is marked in green and extends over all the floors is the wall which was moved. The yellow-marked floor elements were checked for their deflections and the controlled elements were located in the building as depicted in Figure 47.

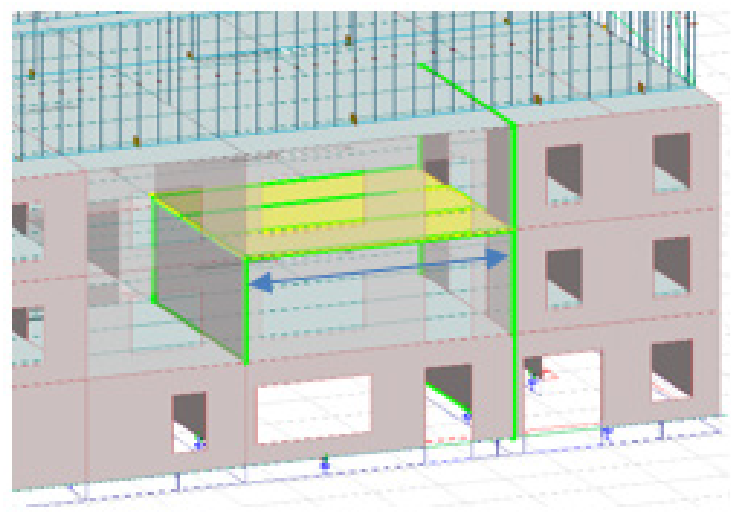

Figure 46. Moved wall

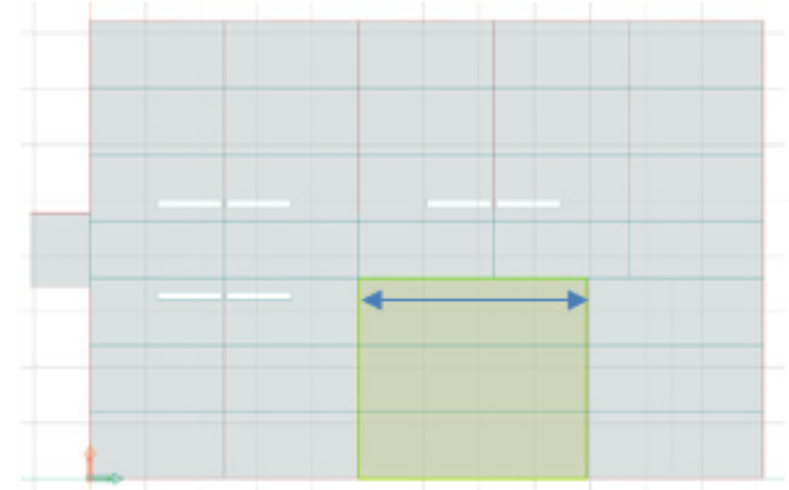

Figure 47. Current element

\subsection{Stability of Building}

Meanwhile, stability of the building was checked. It was shown that the building with both the RC floors ( 250 $\mathrm{mm})$ and CLT floors $(300 \mathrm{~mm})$ was stable based on the stability control in the software. The most critical load combination for the building with the RC floors consisted of LC4ULS which means the load case 4 in the ultimate limit state STR $6.10 \mathrm{~b}$ according to the Swedish national annex of Eurocode 0 (EC0) [19]. The same load combination was the most critical one for the building with the CLT floors as well. However, the stability of the building was decreased with lighter weight and larger deflection of the floors, thus, the results uncovered that the building with the RC floors was more stable than the building with the CLT floors in accordance with the global analysis.

\subsection{Comparison of Results of RC and CLT Floors of Building in Terms of Stresses, Utilisation Ratios and Weights}

According to the compressive and tensile stresses in the $\mathrm{RC}$ and CLT floors, it was witnessed that the RC floors were stiffer generally with higher compressive stresses than the CLT floors, on the other hand, the latter had higher tensile stresses. The higher tensile stresses of the CLT floors than the RC floors were decreased with increasing the cross-section. One reason why some of the $\mathrm{RC}$ floors were subjected to less stresses than the CLT floors in the $\mathrm{x}^{\prime}$-direction was because their capacity across $y^{\prime}$-direction was used more than that in the CLT floors.

The summarised results are presented in Table 2 for the $\mathrm{RC}$ and CLT floors of the building in terms of the utilisation ratios and weights. As was mentioned previously, when the utilisation ratios of the CLT floors were too high, they were lowered by reinforcing solutions such as adding beams under the floors or moving the walls of the large spans. Also, the thickness of the CLT floors was needed to be increased to have lower utilisation ratios than $100 \%$.

Total weights of the RC floors with the thickness of $250 \mathrm{~mm}$ and the CLT floors with the thickness of $300 \mathrm{~mm}$ were obtained as $765 \mathrm{t}$ and $150 \mathrm{t}$, respectively which implied having a difference of $615 \mathrm{t}$. Lower weight of CLT is advantageous which can lead to fast construction processes compared with $\mathrm{RC}$ that requires installation of reinforcement and drying time. 
Table 2. Comparison of utilisation ratios and weights of RC and CLT floors of building

\begin{tabular}{|c|c|c|c|c|c|c|}
\hline \multirow{2}{*}{ Plan } & \multicolumn{2}{|c|}{ RC floor with thickness of $250 \mathrm{~mm}$} & \multicolumn{2}{c|}{$\begin{array}{c}\text { CLT floor with thickness of } 260 \mathrm{~mm} \\
\text { after reinforcing }\end{array}$} & \multicolumn{2}{c|}{ CLT floor with thickness of $300 \mathrm{~mm}$} \\
\cline { 2 - 7 } & Utilisation ratio (\%) & Weight (t) & Utilisation ratio (\%) & Weight (t) & Utilisation ratio (\%) & Weight (t) \\
\hline Plan 1 & 97 & 255 & 92 & 44 & 90 & 50 \\
\hline Plan 2 & 94 & 255 & 94 & 44 & 90 & 50 \\
\hline Plan 3 & 99 & 255 & 99 & 44 & 99 & 50 \\
\hline Total & & 765 & & 132 & & 150 \\
\hline
\end{tabular}

\subsection{Comparison of Results from Calculations Based on Eurocodes and StruSoft FEM-Design Software for Building with RC and CLT Floors}

The obtained results for the RC floors with the thickness of $250 \mathrm{~mm}$ from calculations following EC2 and the numerical analysis are compared in Table 3. The results are for primary bending reinforcements in the span and utilisation ratios in the primary $\mathrm{x}^{\prime}$ direction.

Table 4 compares the obtained results for the CLT floors from calculations following EC5 and the numerical study. The calculations were performed on the utilisation ratios for the bending stress in $\mathrm{x}^{\prime}$ direction and shear stress of the CLT floors with the thickness of $300 \mathrm{~mm}$.

As can be witnessed from Tables 3 and 4, the results achieved from the calculations on the basis of Eurocodes (EC2 and EC5) and the numerical investigations were very close to each other, which verified the good accuracy of the numerical investigations of this study.

Table 3. Comparison of results for RC floors based on EC2 and numerical investigation

\begin{tabular}{|c|c|c|}
\hline Features & EC2 & Numerical investigation \\
\hline Bending moment & $26.6 \mathrm{kNm} / \mathrm{m}$ & $23.96 \mathrm{kNm} / \mathrm{m}$ \\
\hline Required reinforcement & $280 \mathrm{~mm}^{2} / \mathrm{m}$ & $256 \mathrm{~mm}^{2} / \mathrm{m}$ \\
\hline Applied reinforcement & $524 \mathrm{~mm}^{2} / \mathrm{m}$ & $524 \mathrm{~mm}^{2} / \mathrm{m}$ \\
\hline $\begin{array}{c}\text { Utilisation ratio of } \\
\text { reinforcements }\end{array}$ & $53 \%$ & $49 \%$ \\
\hline
\end{tabular}

Table 4. Comparison of results for CLT floors based on EC5 and numerical investigations

\begin{tabular}{|c|c|c|}
\hline Features & $\begin{array}{c}\text { EC5 } \\
\text { Utilisation ratio (\%) }\end{array}$ & $\begin{array}{c}\text { Numerical investigation } \\
\text { Utilisation ratio (\%) }\end{array}$ \\
\hline Bending stress & 30 & 28 \\
\hline Shear stress & 49 & 53 \\
\hline
\end{tabular}

\section{Conclusions}

This paper compared the CLT and RC floors in an existing building considering their load-bearing properties, to check if the RC floors can be replaced with the CLT floors having the same span and thickness. The research work was done by the use of the StruSoft FEM-Design software. It was revealed that the CLT floor with the thickness of $260 \mathrm{~mm}$ can replace the RC floor with the thickness of $250 \mathrm{~mm}$ adopting a few reinforcing solutions.
However, it was shown that the CLT floors with the thickness of $300 \mathrm{~mm}$ could carry the design loads without reinforcing having acceptable deflections. Regarding the stability control of the building, the building with both of the CLT and RC floors was stable. The CLT floors of the building turned out to be significantly lighter than the RC floors. By using the CLT floors in the building, loads on the load-bearing parts and foundations could drastically be reduced as the weight of the materials is a decisive factor. This issue can make a considerable difference to the stresses in the soil which in turn can reduce the costs in terms of the foundation work, transport, etc. Comparisons of the obtained results from the numerical investigation with those from the calculations based on EC2 and EC5 uncovered the good accuracy of the numerical results.

\section{REFERENCES}

[1] R. Brandner, G. Flatscher, A. Ringhofer, G. Schickhofer, A. Thiel, Cross laminated timber (CLT): overview and development, European Journal of Wood and Wood Products, Vol. 74, 331-351, 2016.

[2] M. Jeleč, D. Varevac, V. Rajčić, Cross-laminated timber (CLT) - a state of the art report, Građevinar, Vol. 70 , No. 2, 75-95, 2018.

[3] R. Steiger, A. Gülzow, C. Czaderski, M. T. Howald, P. Niemz, Comparison of bending stiffness of cross-laminated solid timber derived by modal analysis of full panels and by bending tests of strip-shaped specimens, European Journal of Wood and Wood Products, Vol. 70, 141-153, 2012.

[4] S. Breneman, A state of the art review of cross-laminated timber floor systems, SEAOC, Convention Proceedings, 2014.

[5] A. Vilguts, D. Serdjuks, L. Pakrastins, Design methods of elements from cross-laminated timber subjected to flexure, Procedia Engineering, Vol. 117, 10-19, 2015.

[6] M. F. Laguarda Mallo, O. Espinoza, Awareness, perceptions and willingness to adopt cross-laminated timber by the architecture community in the United States, Journal of Cleaner Production, Vol. 94, 198-210, 2015.

[7] K. Lewis, B. Basaglia, R. Shrestha, K. Crews, The use of cross laminated timber for long span flooring in commercial buildings, World Conference on Timber Engineering, Austria, 2016. 
[8] L. Franzoni, A. Lebée, F. Lyon, G. Forêt, Elastic behavior of cross laminated timber and timber panels with regular gaps: Thick-plate modeling and experimental validation, Engineering Structures, Vol. 141, 402-416, 2017.

[9] R. Brandner, Cross laminated timber (CLT) in compression perpendicular to plane: Testing, properties, design and recommendations for harmonizing design provisions for structural timber products, Engineering Structures, Vol. 171, 944-960, 2018.

[10] O. A. B. Hassana, F. Öberg, E. Gezelius, Cross-laminated timber flooring and concrete slab flooring: A comparative study of structural design, economic and environmental consequences, Journal of Building Engineering, Vol. 26, 100881, 2019.

[11] S-J. Pang, G. Y. Jeong, Effects of combinations of lamina grade and thickness, and span-to-depth ratios on bending properties of cross-laminated timber (CLT) floor, Construction and Building Materials, Vol. 222, 142-151, 2019.

[12] M. Valdes, G. F. Giaccu, D. Meloni, G. Concu, Reinforcement of maritime pine cross-laminated timber panels by means of natural flax fibers, Construction and Building Materials, Vol. 233, 117741, 2020.

[13] A. Sotayo, D. F. Bradley, M. Bather, M. Oudjene, I.
El-Houjeyri, Z. Guan, Development and structural behaviour of adhesive free laminated timber beams and cross laminated panels, Construction and Building Materials, Vol. 259, 119821, 2020.

[14] M. Sciomenta, L. Spera, C. Bedon, V. Rinaldi, M. Fragiacomo, M. Romagnoli, Mechanical characterization of novel homogeneous Beech and hybrid Beech-Corsican Pine thin cross-laminated timber panels, Construction and Building Materials, Vol. 271, 121589, 2021.

[15] C. Wang, W-S. Chang, W. Yan, H. Huang, Predicting the human-induced vibration of cross laminated timber floor under multi-person loadings, Structures, Vol. 29, 65-78, 2021.

[16] M. C. D. M. Pereira, L. A. P. Sohier, T. Descamps, C. C. Junior, Doweled cross laminated timber: Experimental and analytical study, Construction and Building Materials, Vol. 273, 121820, 2021.

[17] EN 1992-1-1 (2004): Eurocode 2: Design of concrete structures - Part 1-1: General rules and rules for buildings.

[18] EN 1995-1-1 (2004): Eurocode 5: Design of timber structures - Part 1-1: General - Common rules and rules for buildings.

[19] EN 1990 (2002): Eurocode - Basis of structural design. 